\title{
Active Q Flux Concept for Sensorless Control of Synchronous Reluctance Machines
}

This paper was downloaded from TechRxiv (https://www.techrxiv.org).

\section{LICENSE}

CC BY 4.0

SUBMISSION DATE / POSTED DATE

28-08-2021 / 02-09-2021

\section{CITATION}

zhang, zhendong; Lamb, Jacob M. (2021): Active Q Flux Concept for Sensorless Control of Synchronous Reluctance Machines. TechRxiv. Preprint. https://doi.org/10.36227/techrxiv.16529553.v1

DOI

10.36227/techrxiv.16529553.v1 


\title{
Active Q Flux Concept for Sensorless Control of Synchronous Reluctance Machines
}

\author{
Zhendong Zhang, Member, IEEE, Jacob Lamb, Member, IEEE
}

\begin{abstract}
This paper proposes a new scheme to use active flux on q-axis for sensorless control of synchronous reluctance machines (SynRM). Conventionally, "Active Flux" on d-axis is adopted to convert a salient pole machine into a fictitious non-salient pole machine. However, the injected d-axis flux can deteriorate high frequency injection (HFI) sensorless control performance or even run the system into unstable region at low speed. This paper demonstrates active flux on q-axis can support back-EMF sensorless control at high speed and improve low speed HFI performance substantially. A seamless transition from HFI sensorless method to back-EMF voltage method is attained after adopting the proposed active $q$ flux. Experiment results are used to validate the proposed method.
\end{abstract}

Index Terms-Active flux, back-EMF, high frequency injection (HFI), saliency, sensorless control, synchronous reluctance machines (SynRM).

\section{INTRODUCTION}

$\mathrm{S}_{\mathrm{h}}^{\mathrm{Y}}$ YNCHRONOUS reluctance machines (SynRM) exhibit higher efficiency and better torque density as compared to induction machines (IM) [1], and better cost-reduction, less resource security risk, and higher reliability as compared to permanent-magnet (PM) machines [2]. Thanks to these advantages, SynRM are becoming more popular, especially for industrial application where sizing is not a deterministic factor. Since both SynRM and IM do not use expensive rare-earth materials, replacing the existing IM with more efficient SynRM is demonstrated to be a feasible and rewarding solution.

SynRM are one type of salient-pole machine which have structural similarities towards widely used interior permanent magnet (IPM) machines. However, SynRM control is distinct from IPM control, mainly due to the self-saturation and cross-saturation between $d$ and $q$ axes and the lack of rotor permanent magnets.

Sensorless control of SynRM has been investigated by a number of authors, and the hybrid high frequency injection (HFI) and back-EMF sensorless methods are widely adopted [3]-[9]. The same sensorless control methods that applies to IPM machines, whether it is HFI method or back-EMF method,

Manuscript received Month $\mathrm{xx}, 2 \mathrm{xxx}$; revised Month $\mathrm{xx}, \mathrm{xxxx}$; accepted Month $x, x x x x$. This work was supported in part by the ... Department of $x x x$ under Grant (corresponding author: Zhendong Zhang).

Zhendong Zhang and Jacob Lamb are with Rockwell Automation, Mequon, WI 53092, USA (e-mail: zhendong.zhang@ieee.org; jlamb@rockwellautomation.com) can be deployed to SynRM potentially. However, self-saturation and cross-saturation of SynRM could complicate the implementation. In particular, the HFI sensorless method, which relies on machine saturation level, requires re-evaluation and re-commissioning. A reference $q$-axis current, saturating $q$-axis iron, is reported to improve HFI sensorless performance at low speed [5].

However, all these reference methods require a minimum magnetizing current ( $d$-axis current) to flux-up the machine for the purpose of providing "active flux" for angle detection. The active flux concept [10], assisting the back-EMF based sensorless control for a salient-pole machine, is proposed and therefore rotor position can be retrieved directly just as a non-salient pole machine. Despite rotor position is only detected by HFI method at low speed, this active flux is still maintained for the purpose of a seamless transition from HFI scheme to back-EMF scheme and vice versa. However, injecting $d$-axis current can reduce motor saliency substantially or even reverse motor saliency, which could deteriorate HFI sensorless performance since the angle detection accuracy of HFI method heavily relies on machine saliency.

Instead of doing sensorless control using $d$-axis current induced active flux above, this paper proposes a new approach that uses $q$-axis current induced flux for SynRM back-EMF based sensorless control. Conceptually, $q$-axis current is considered as torque current, which should not be used for flux excitation and sensorless control. However, it is verified by experimental results that $q$-axis current induced flux offers not only sensorless capability but also benefits compared to $d$-axis current. This new $q$-axis current induced flux is defined as "active $q$ flux" throughout this paper.

This paper is organized as follows. Section II reviews the background knowledge about SynRM. Section III evaluates the conventional scheme of doing SynRM sensorless control. The active $q$ flux concept is proposed in Section IV and sensorless control using active $q$ flux concept is presented. In Section V, experimental data validate that the proposed active $q$ flux concept can improve HFI angle detection stability while maintain sensorless performance based on back-EMF method.

\section{SYNRM BACKGROUND}

In this section, the rotor structures of both SynRM and IPM are compared, and SynRM mathematical model is reviewed. Additionally, the flux vector control (FOC) of SynRM below base speed using maximum torque per ampere (MTPA) scheme is briefly described. 


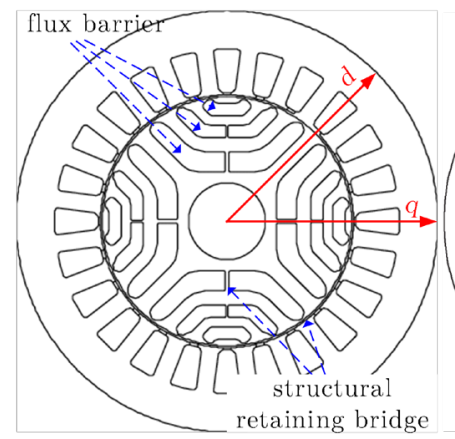

(a)

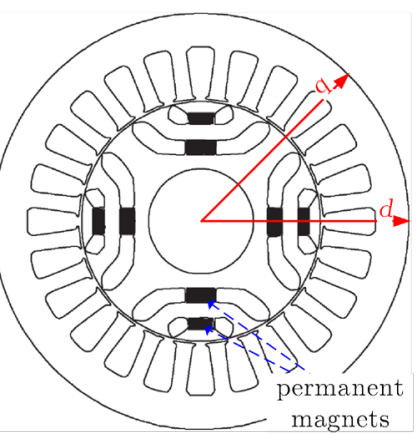

(b)
Fig. 1. SynRM and IPM motor stator and rotor cross-section lamination [22].

\section{A. SynRM and IPM Rotor Structure Comparison}

Unlike IPM machines with magnets on the rotor, the rotor of SynRM is made of steel lamination only, either in transverse direction or in axial direction. Fig. 1(a) shows the cross-section view of the stator and rotor laminations of a typical 4 pole SynRM. Its stator is very similar to IM and PM machines. A few layers of flux barrier create high reluctance radial path. Normally, $d$-axis is defined towards the high permeance path (iron dominant), while $q$-axis aligns to the low permeance path (air dominant). Fig. 1(b) shows the cross-section of an IPM machine, which possesses similar stator and rotor structure as compared to that in Fig. 1(a), except for the highlighted permanent magnets. Note in particular that the definition of $d$ and $q$ axes for an IPM machine in Fig. 1(b) is different from that for a SynRM in Fig. (a). D-axis of an IPM machine is defined along low permeance path and $q$-axis is defined along high permeance path.

\section{B. SynRM Mathematical Model}

SynRM mathematical model in $d q$ axes rotor reference frame is specified in (1)-(3).

$$
\begin{aligned}
& \begin{cases}= & +-- \\
= & +\square+\end{cases} \\
& \left\{\begin{array}{l}
=(, \quad)=\quad+\quad=(, \quad) \text {. } \\
=(,,)=(, \quad) .
\end{array}\right.
\end{aligned}
$$

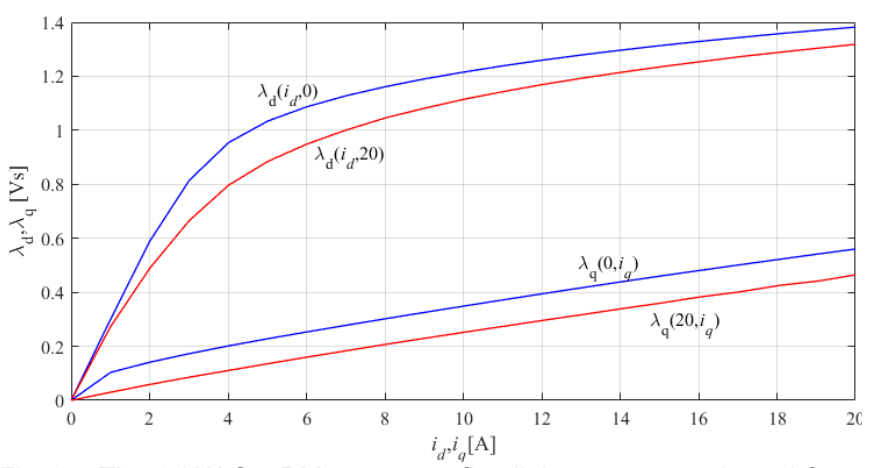

Fig. 2. The 3-kW SynRM current-to-flux-linkage map evaluated from experiments.

TABLE I

SYNRM SPECIFICATIONS

\begin{tabular}{lc}
\hline \hline \multicolumn{2}{c}{ SynRM motor under test } \\
\hline Rated Power & $3.0 \mathrm{~kW}$ \\
Rated Speed & $1500 \mathrm{rpm}$ \\
Rated Torque & $19 \mathrm{~N} \cdot \mathrm{m}$ \\
Nominal Line-Line Voltage (rms) & $380 \mathrm{~V}$ \\
Nominal Current (rms) & $7.1 \mathrm{Arms}$ \\
Switching Frequency & $4 \mathrm{kHz}$ \\
Number of poles & $4 \mathrm{poles}$ \\
\hline \hline &
\end{tabular}

where is stator resistance, is rotor frequency, is the pole pairs, and are stator $d q$ voltages, and are stator $d q$ currents, and are stator $d q$ voltages, and denotes electromagnetic torque. In (2), and are the $d q$ axes self-inductance. is $d$-axis cross saturation inductance induced from $q$-axis current, and is the $q$-axis cross saturation inductance induced from $d$-axis current. Both $d q$ axes self-inductance and cross saturation inductance can be lumped together as $(, \quad)$ and $(, \quad)$ in (2). Equation (2) can be expressed using two 2-D flux maps with, as the index axes, namely current-to-flux-linkage map. Fig. 2 shows the flux map of the SynRM under test and its full specification is shown in Table I. The flux map defines the basic characteristic of this SynRM and provides data necessary for control. Fig. 2 is identified through off-line dyne test, though it can also be evaluated through finite element analysis or online

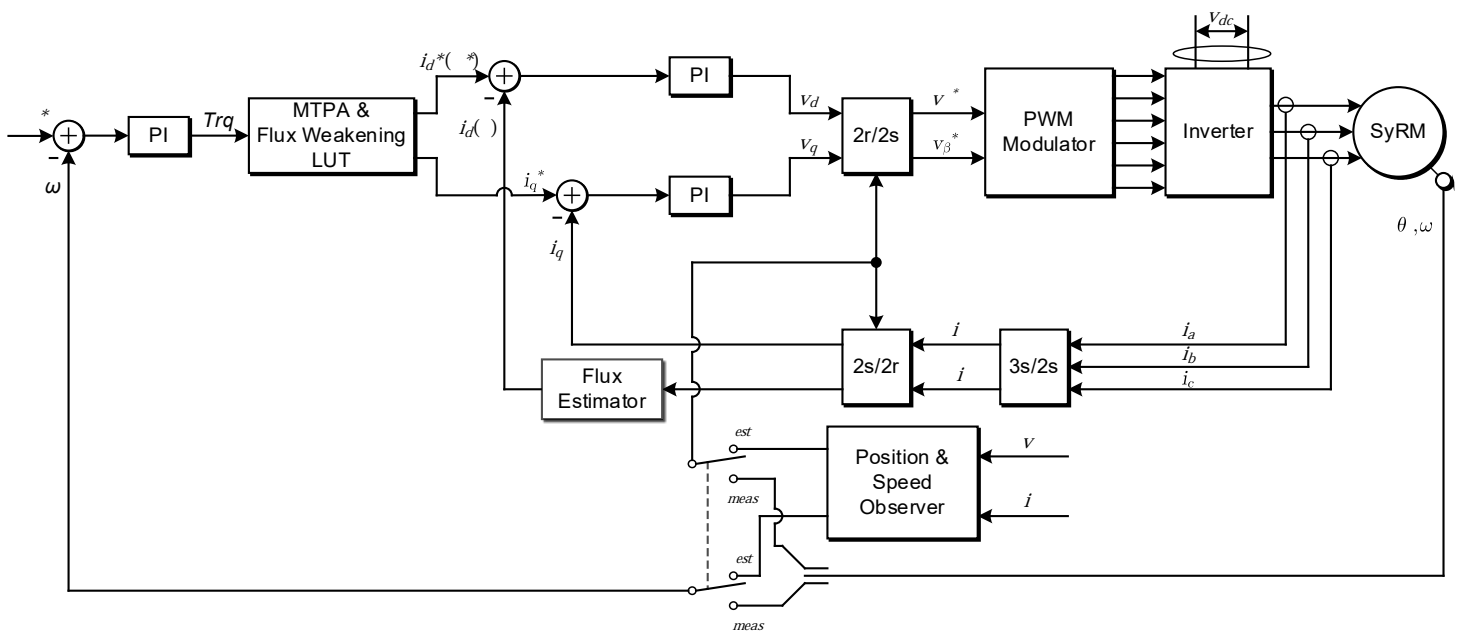

Fig. 3. SynRM machine FOC control block diagram. 
self-commissioning method [11], [12].

\section{FOC Vector Control Scheme}

The FOC scheme of a SynRM is shown in Fig. 3. FOC can be implemented with position sensor or without position sensor. If sensorless control is preferred, a position and speed observer is needed to estimate the rotor position information out of machine voltages and currents. For flux and torque control, the conventional $d q$ dual axes current regulators are one of the solutions. A flux regulator, replacing the $d$-axis regulator, is reported in [13], considering $d$-axis as the flux axis and $q$-axis as the torque axis. A $d$-axis flux estimator is then needed to assist the implementation of this method.

Low-speed maximum torque per ampere (MTPA) control and high-speed flux weakening control are established control strategy for salient pole machines. These optimal current control trajectories on - vector plane can be obtained based on the map in Fig. 2. This paper focuses on sensorless control and MTPA operation below base speed. The constant torque curve and MTPA curve of the SynRM under test are plotted in Fig. 4.

\section{SYNRM SENSORLESS CONTROL}

As mentioned earlier, sensorless algorithms that apply to IPM machines need reevaluation and potential adjustments to ensure reliable operation for SynRM. This section first reviews the existing sensorless control methods for SynRM. The unique challenges of controlling a SynRM is explained, and the limitations of existing methods are explored.

\section{A. Low Speed High Frequency Injection}

For a salient-pole machine, HFI can be used to extract rotor position at low speed [14], [15]. All HFI methods that applies to IPM machines, whether it is sinusoidal waveform injection [16], or the pulsating voltage injection [17], [18], or the square waveform injection [19], should be viable for SynRM. However, $d q$ axes self-saturation and cross-saturation does affect angle detection substantially [20] and will be studied in-depth below.

\section{B. Combined Active Flux Concept and HFI Methods}

HFI method is normally applied at low speed to prevent

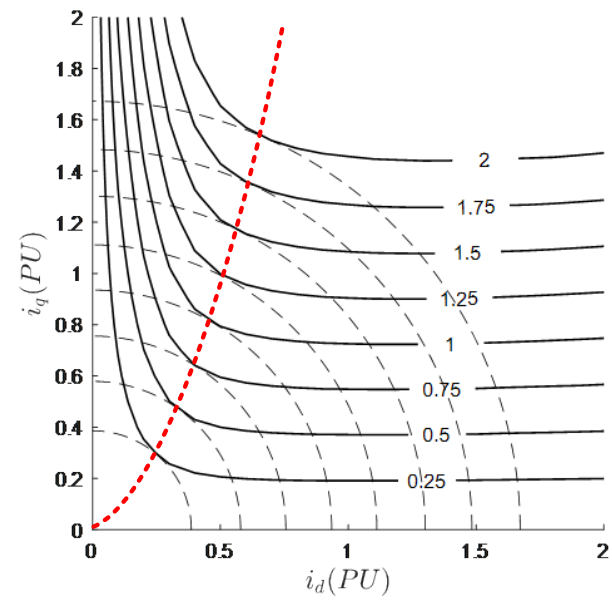

Fig. 4. 3-kW SynRM machine constant torque curve and MTPA curve. Red dotted line is MTPA trajectory, solid lines are torque contours, dashed lines are current magnitude contours. aliasing between fundamental component and high frequency component. Back-EMF voltage based sensorless takes over after the motor accelerates over certain threshold speed. "Active flux" model [10] is normally employed to turn an anisotropic machine into a fictious isotropic machine. It is expressed as

$$
\begin{aligned}
=- & =\left(\begin{array}{ll}
- & -
\end{array}\right) \\
& =-\quad=0
\end{aligned}
$$

where is active flux, and are active flux on $d q$ axes. As illustrated in Fig. 5, active flux is derived graphically on $d q$ axes vector plane based upon (4), where the vector in green dot-dash line is to derive active flux from stator flux . Thus, the voltage equation in stationary reference frame and the torque equation are derived as

$$
\begin{aligned}
& {[\quad]=(+)[]+\left[\begin{array}{ll}
- &
\end{array}\right]} \\
& =\frac{3}{2}[(-\quad) \quad] \\
& =\frac{3}{2}
\end{aligned}
$$

where and are stator $\beta$ voltage, and are stator $\beta$ current, is rotor electrical angle. Simply applying integration towards voltage model in (5), equations (8)-(10) show how to calculate rotor position using the active flux concept.

$$
\begin{aligned}
& =\int\left(\begin{array}{ll}
- & )
\end{array}\right. \\
& =\int(-\quad) \\
& \begin{cases}= & - \\
& =\end{cases} \\
& =\quad(-)
\end{aligned}
$$

where and are stator $\beta$ flux linkage. and are active flux on $\beta$ axes. These equations explain the basic mathematics for rotor position estimation, while more advanced schemes such as observer-based estimation algorithms can be deployed.

A fusion logic shown in Fig. 6 is then adopted to do a smooth transition between HFI scheme at low speed and back-EMF scheme at high speed when motor accelerates or decelerates.

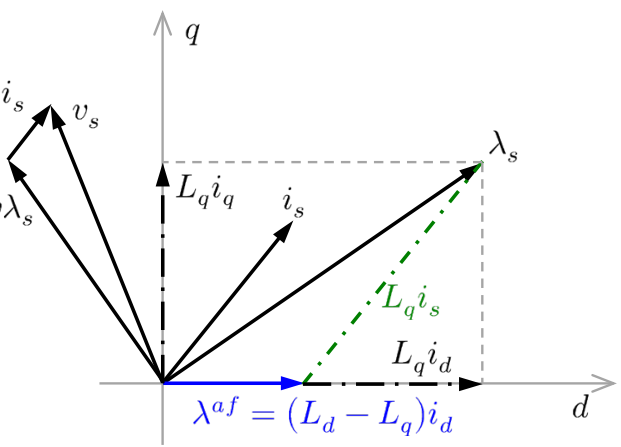

Fig. 5. Active flux definition in $d q$ axes frame. 


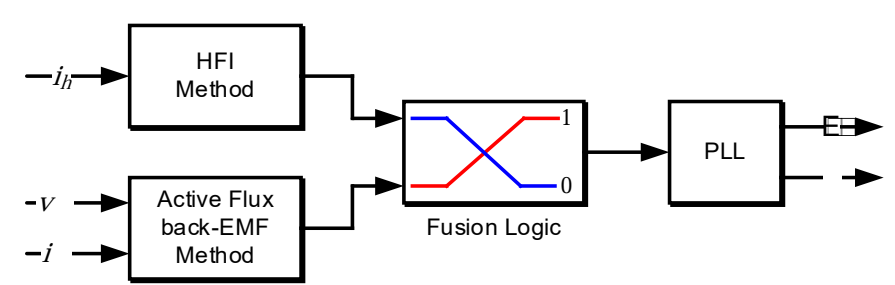

Fig. 6. Estimated angle fusion from HFI method and active flux method.

\section{MTPA and Minimum Excitation Current Selection}

The MTPA curve in Fig 4 shows the operating trajectory with highest torque output while lowest current magnitude. When near zero torque is commanded, both and command currents are close to the origin based on MTPA curve. HFI sensorless operation of SynRM becomes challenging at this region mainly due to two reasons.

1). When is close to zero, the active flux vector depicted in Fig. 5 and (4) is also adjacent to zero, and therefore back-EMF sensorless control that requires enough active flux may not offer reliable angle detection under this circumstance.

2 ). When and are both around zero, neither $d$-axis nor $q$-axis flux paths in Fig.1(a) are saturated. In this case, the transient inductance between $d$ and $q$ axes could stay close, which indicates a near unity saliency ratio ( / ). However, HFI method requires a minimum saliency ratio for reliable rotor position detection. This will be further expanded below.

To overcome issue 1), a minimum current is pre-selected to guarantee enough active flux for back-EMF based sensorless angle detection [4], [7]. It may also improve sensorless performance caused by issue 2). However, it could run into the risk of entering unstable region when HFI is enabled, which is dependent on machine design characteristics. Though a saturation current is proposed in [5] to resolve issue 2), a 2-D hysteresis transition scheme is needed to transit from saturation current at low speed to minimum current at high speed, which can complicate system design and introduce extra disturbance into system.

\section{Absence of Saliency and Reverse Saliency}

For each $d$-axis flux in Fig. 2 , it has a knee point $(\approx$ 4 ), where transient inductance is markedly different before and after the knee point. This is attributes to the fact that $d$-axis lamination steel starts to saturate when excessive current is injected. In other words, SynRM gradually lose saliency when more current is injected. Fig. 7 shows saliency ratio on $d q$ axes current plane, which is derived from the flux map in Fig. 2.

Normally, SynRM HFI angle detection is based on the assumption that . However, this is not always valid on the whole current vector plane. The case when $\approx$ is mentioned in Section $\mathrm{C}$ above. For extreme condition where large and small are injected, the case where $<$ can occur, which is named "reverse saliency". In this case, $d q$ axes defined by HFI detected angle will flip their positions.

Both "absence of saliency" and "reverse saliency" will lead to the failure of reliable and consistent angle detection for any HFI scheme in these regions.

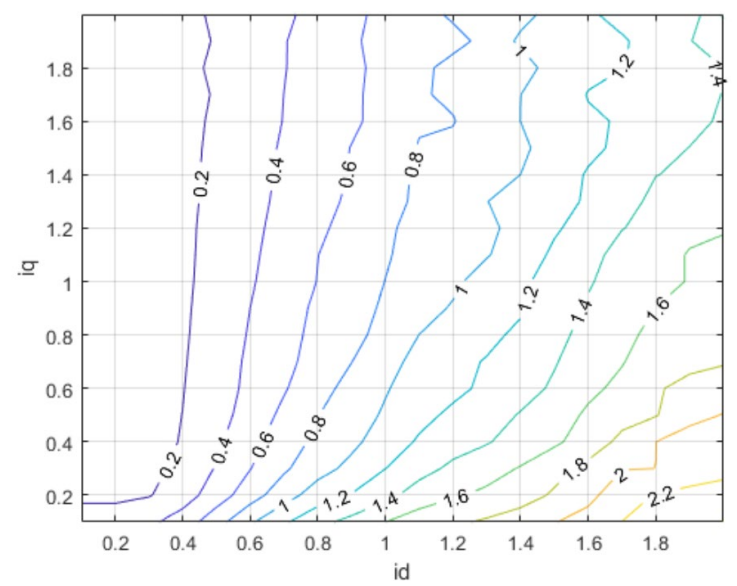

Fig. 7. Saliency ratio on $\mathrm{i}_{\mathrm{d}}-\mathrm{i}_{\mathrm{q}}$ current vector plane based on transient inductance.

\section{E. Stability Region for HFI Sensorless Angle Detection}

Section $\mathrm{C}$ and $\mathrm{D}$ above address stability issue regarding back-EMF and HFI schemes for SynRM sensorless control. The minimum excitation resolves back-EMF scheme issue, while the stability issue regarding HFI operation remains. In this section, three HFI instability regions are highlighted in Fig. 8 with each region explained below to assist the development of new solution.

Region (1): Neither $d$ or $q$ axes are saturated.

Issue 2) in Section $\mathrm{C}$ is referring to the same instability region, which is known as rib effect [21]. Q-axis needs structural retaining ribs between each flux barrier layer to enhance the structural strength of the rotor lamination as shown in Fig. 1(a). These tiny ribs create a low magnetic resistance path along $q$-axis. These ribs will soon become saturated when very little current is injected, which certainly helps create rotor saliency. Otherwise, the rotor will not show enough saliency for reliable HFI angle detection when the current vector falls inside zone (1) shown in Fig. 8.

Region (2): $d$ and $q$ axes are both saturated.

Large torque requires large and currents output. According to the flux curve in Fig. 2, both $d$ and $q$ axes flux paths are saturated in this case, which results the absence of saliency.

Region (3): $d$-axis is saturated, but $q$-axis is not.

HFI works well assuming . When large $d$-axis current is injected while no $q$-axis current is injected, the reverse relationship $<$ holds. In this case, HFI detected angle has $90^{\circ}$ tracking error.

To avoid all HFI instability regions, the selection of minimum $d$-axis current curve becomes challenging. Fig. 8 shows two min lines (Min $I_{d}$ Line $1 \&$ Min $I_{d}$ Line 2) with different value. Min $\mathrm{I}_{\mathrm{d}}$ Line 1 falls inside unstable regions (2) \& (3), while Min $I_{d}$ Line 2 doesn't. Identifying stable min $I_{d}$ line requires exact knowledge of the plant, which may not be readily available. It is possible that no minimum $d$-axis trajectory can avoid all three regions considering unique machine designs.

Fig 8 shows the region to the left of MTPA curve (excluding Region 1) never falls inside any of these HFI unstable regions mentioned above. However, this operation region cannot satisfy the minimum $d$-axis excitation trajectory, which is 


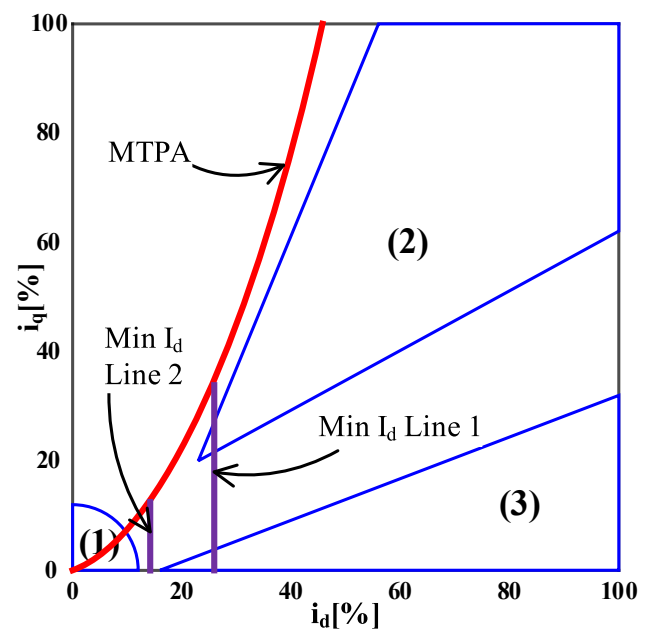

Fig. 8. SynRM HFI unstable regions.

required by back-EMF active flux angle detection. An instantaneous transition from minimum $q$-axis current trajectory to minimum $d$-axis trajectory at the algorithm fusion period elaborated in Section B could be a viable solution to the best. However, it could result in large disturbance, or even worse, transition failure.

\section{Proposed Active Q Flux Concept for SynRm SENSORLESS OPERATION}

Section III reviews sensorless control of a SynRM and stability challenge associated especially for HFI. In this section, a new solution is proposed to address the dilemma that the current trajectories for HFI stable operation and that for back-EMF operation do not align with each other. By adopting the proposed solution, sensorless control performance of a SynRM can be substantially improved.

An IPM machine uses rotor permanent magnet induced $d$-axis flux for back-EMF sensorless control. Since $d$ and $q$ axes are flipped for a SynRM as compared to that for an IPM machine, a SynRM should be able to use flux along $q$-axis for back-EMF based sensorless control if $d$-axis works for an IPM machine. This $q$-axis flux can be generated by injecting $q$-axis stator current.

If above assumption holds, sensorless control using HFI method and back-EMF method can be unified without running into the controversy regarding the stability of operation trajectory shown in Fig. 8.

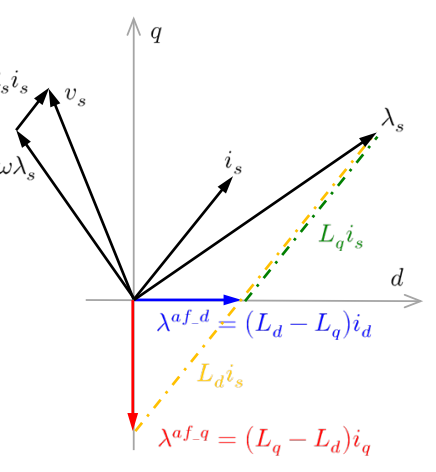

(a)

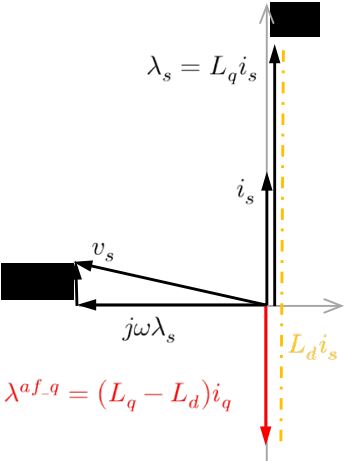

(b)
Fig. 9. Active $q$ flux definition on $d q$ current plane. (a) with both $i_{d}$ and $i_{q}$ current. (b) with only $i_{q}$ current and zero $i_{d}$ current.

\section{A. Proposed Active Q Flux and Sensorless Control}

In this section, "active $q$ flux" concept is proposed to justify the above assumption. Sensorless control based on active $q$ flux concept is evaluated mathematically.

1) Active $Q$ Flux Concept

The conventional active flux concept illustrated in (4) is considered as active $d$ flux, where the final active flux vector

aligns towards $d$-axis. This is shown in Fig. 5. If the green dot dash line ( vector) in Fig. 5 is extended further to intersect $q$-axis as shown in Fig 9(a), a new flux vector from origin to the $q$-axis intersection point (red line with arrow) is defined as "active $q$ flux". Equation (11) shows its mathematical definition, where - is the proposed active $q$ flux, $\quad-$ and $\quad-$ are active $q$ flux on $d q$ axes respectively.

$$
\left\{\begin{aligned}
-=- & =0 \\
-=- & =0=(-)) \cdot=-
\end{aligned}\right.
$$

Fig. 9(a) shows that $\quad-$ aligns itself towards negative $q$-axis. The yellow dashed line that connects to - is vector. Fig 9(b) shows when only $q$-axis current is commanded, active $d$ flux - disappears, but active $q$ flux - still exists. In other words, active $q$ flux is only a function of $q$-axis current. Now, the torque equation in (7) can be rewritten as

$$
=-\frac{3}{2}
$$

\section{2) Sensorless Control using Active $Q$ Flux}

Based upon proposed active $q$ flux concept above, stator $d q$ axes flux vector in (11) can be rewritten as

$$
\left\{\begin{array}{l}
= \\
=\quad+
\end{array}\right.
$$

substituting (13) into (1) gives

$$
\left\{\begin{array}{lllll}
= & +- & - & - & - \\
= & +- & + & +
\end{array}\right.
$$

Considering - as a constant at steady-state and converting $d q$ axes equation (14) into axes yields

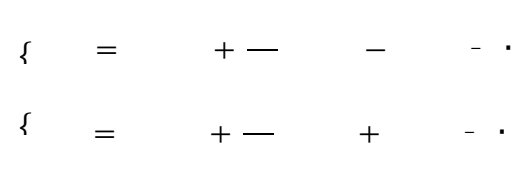

Adopting the same rotor position estimation scheme presented in Section III.B, rotor position $\theta$, using active $q$ flux concept, can be calculated as

$$
\begin{aligned}
& =\frac{\frac{-\cdot}{-\cdot}+\overline{2}}{\int\left(-\frac{1}{2}\right)-}+\overline{2}
\end{aligned}
$$

Equation (16) is translated into the control block diagrams shown in Fig. 10, where a $\pi / 2$ is added to final angle 


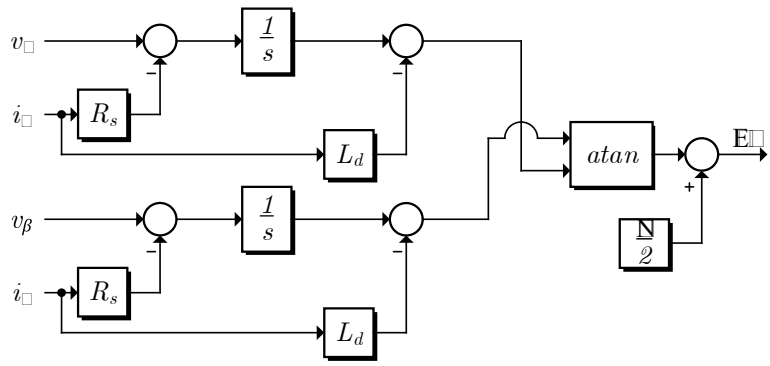

Fig. 10. Rotor position estimation based on proposed active $q$ flux. estimation output that accounts for the orientation of active $q$ flux along negative $q$-axis shown in Fig. 9(a).

\section{B. SynRM Back-EMF Sensorless using Minimum Q-axis Current Excitation}

The proposed active $q$ flux demonstrates that rotor position can be estimated using $q$-axis current induced flux. Instead of maintaining a minimum $d$-axis current at the risk of destabilizing HFI sensorless control, a minimum $q$-axis current is retained at low torque condition as shown in Fig 11. Now, the current works on the $q$-axis limited excitation curve (green) at low torque condition and transits to MTPA curve (red) once large torque command is issued.

Comparing Fig. 11 with Fig. 8, this minimum $q$-axis current bypasses all HFI unstable region shown in Fig 8, which serves as the perfect operational trajectory for HFI and back-EMF integrated sensorless control.

\section{Difference between Proposed Active Q Flux and Conventional Active D Flux.}

There are a few differences regarding back-EMF based sensorless control between using the proposed active $q$ flux vs conventional active $d$ flux.

1). In Fig. 9(a), active $q$ flux lags active $d$ flux by 90 electrical degrees, which indicates $90^{\circ}$ estimated angle difference. This is compensated in (16) and Fig. 10.

2 ). Since $q$-axis inductance is smaller than $d$-axis inductance, for the same amount of current, the $q$-axis induced flux will be lower than $d$-axis. Therefore, the transition speed from HFI to back-EMF may need to be adjusted higher for $q$-axis injection so back-EMF sensorless method will not

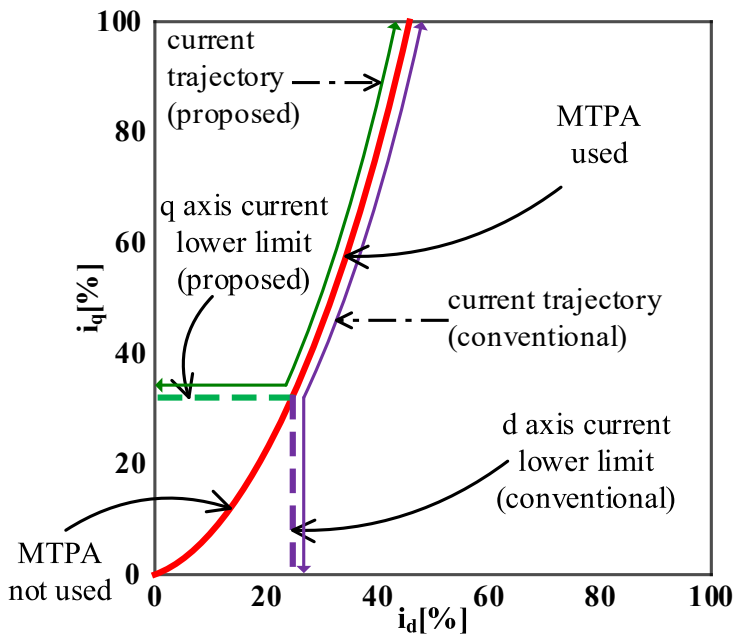

Fig. 11. Proposed minimum $q$-axis current trajectory. fail due to insufficient back-EMF voltage.

\section{EXPERIMENT RESULTS}

Experimental data are collected to demonstrate the proposed active $q$ flux concept and its enhancement towards sensorless control. The specification of the SynRM motor under test is shown in Table. I, and the overall system control block diagram and sensorless control diagram are shown in Fig. 4 and Fig. 10, respectively. Fig. 12 shows the dyne setup used for this demonstration, where speed regulation is achieved using the dyne for all the tests below.

Four experiments are conducted, where experiments A and B compare sensorless angle estimation using HFI method under no load (zero torque) and light load ( $25 \%$ torque) conditions, and experiments $\mathrm{C}$ and D look at back-EMF based sensorless angle estimation using active $d$ flux and the proposed active $q$ flux under no load and full load conditions. The annotations for different curves in Fig .14 to Fig. 17 are listed as phase a current. phase $b$ current. encoder angle feedback. estimated angle feedback using active $d$ flux. estimated angle feedback using active $q$ flux. final estimated angle feedback. angle error

\section{A. HFI with Zero Torque Output (5Hz 150rpm)}

The constant torque curve in Fig 4 shows SynRM outputs zero torque when the current operation point is either on the $d$-axis or $q$-axis. In this experiment, three operational points are selected to compare HFI sensorless angle output.

Fig .13(a) compares HFI estimated angle versus encoder feedback angle when drive operates at the origin on current vector plane, as explained in Section III.E and in Fig 8. The estimated angle shows low order harmonics, which is confirmed by in Fig .13(a). Meanwhile, a constant angle error (more than $20^{\circ}$ ) is observed in

Fig .13(b) shows the same waveforms after injecting $40 \%$ current and 0 current. The ripple on the estimated angle becomes higher in frequency but smaller in peak-to-peak amplitude. Furthermore, the estimated angle error shows less average value.

On the other hand, Fig. 13(c) shows the waveforms with 0 and $40 \%$. The estimated angle shows almost perfect saw-tooth triangle without noticeable oscillation. The estimated

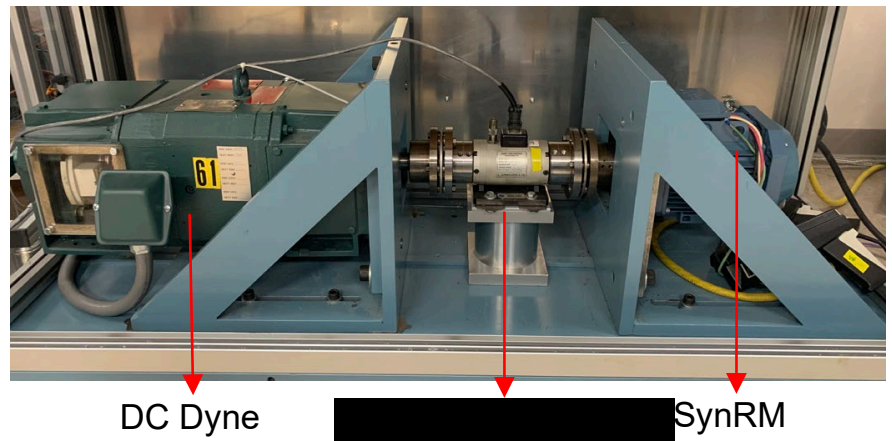

Fig 12. Experiment Dyne Setup. 


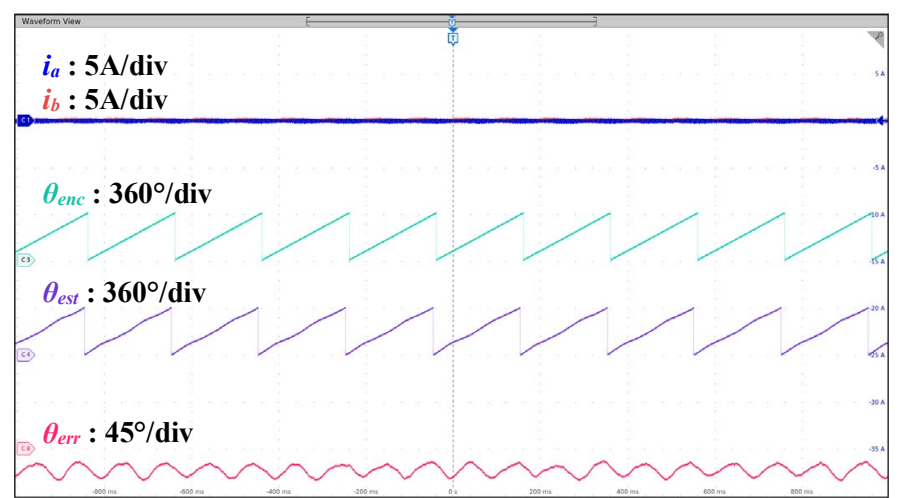

$(\mathrm{a})$
$\boldsymbol{i}_{a}: 5 \mathrm{~A} / \mathrm{div} i_{b}: 5 \mathrm{~A} / \mathrm{div}$

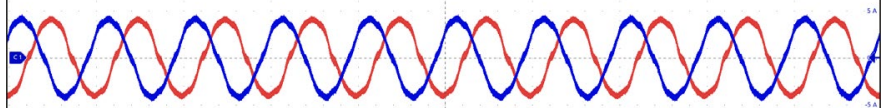

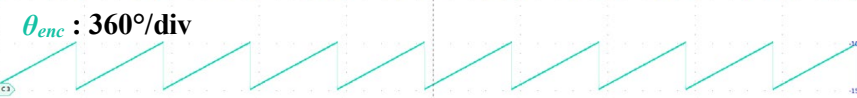

$\theta_{\text {est }}: 360 \%$ div

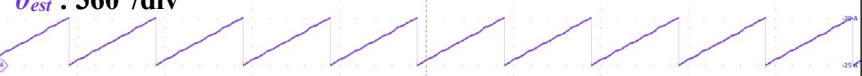

$\theta_{\text {err }}: 45^{\circ} / \mathrm{div}$

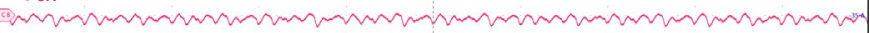

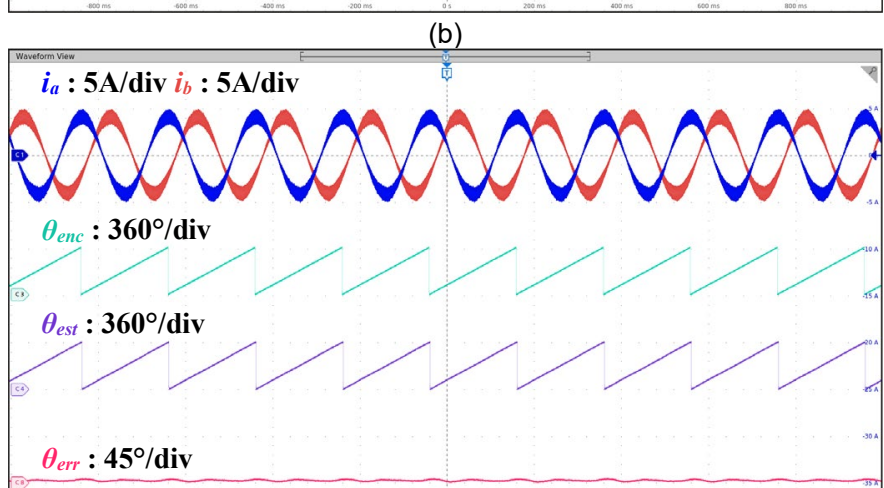

(c)

Fig. 13. HFI angle detection with zero torque output. (a). Original with 0 $\mathrm{i}_{\mathrm{d}}$ and $0 \mathrm{i}_{\mathrm{q}}$. (b) Active $\mathrm{d}$ flux with $40 \% \mathrm{i}_{\mathrm{d}}$ current and zero $\mathrm{i}_{\mathrm{q}}$ current. (c) Active $q$ flux with $40 \% i_{q}$ and zero $i_{d}$ current. Horizontal axis scale: 200ms/div

angle error is very close to zero with minimum ripple on it.

The improvements can also be identified from comparing the measured phase A and phase B currents in both Fig 13(b) and Fig 13(c). In Fig. 13(b), HFI injected harmonic currents show even current ripple at different rotor position, which suggests a small saliency ratio between $d$ and $q$ axes. This agrees with the analysis in Section III.D and Section III.E, where the injected $d$-axis current decreases saliency ratio. However, Fig 13(c) shows very promising current waveforms after injecting $q$-axis current since the variation of current waveform thickness clearly tells the saliency is enhanced for reliable angle detection. The excessive ripple on estimated angle acts as disturbance to the system, which causes output torque ripple.

In conclusion, injecting $q$-axis current (minimum $q$-axis current excitation) can substantially improve sensorless control angle detection accuracy as compared to zero current injection

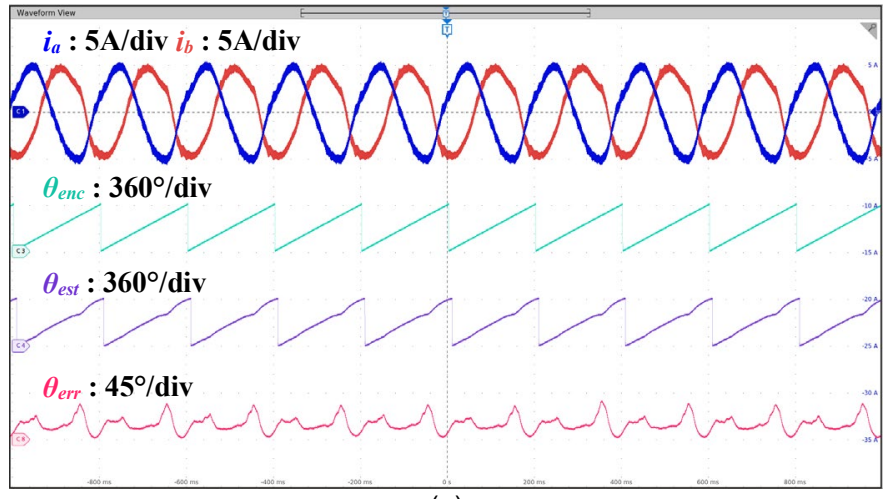

(a)

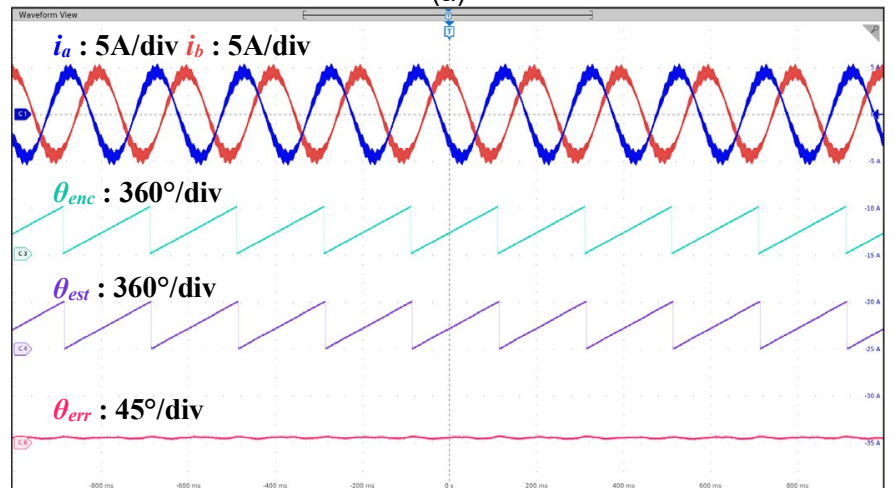

(b)

Fig. 14. HFI angle detection with $25 \%$ rated load. (a) $=4,=$ $2.23 \cdot$ (b) $=1.76,=4.0$. Horizontal axis scale: $200 \mathrm{~ms} / \mathrm{div}$

or $d$-axis current injection when zero torque output is commanded.

\section{B. HFI with Low Torque (25\% rated) Output $(5 \mathrm{~Hz}$ 150rpm)}

To further demonstrate the improvement toward HFI sensorless control using $q$-axis current injection, a small torque ( $25 \%$ rated) is applied. Fig 14 shows two operational cases. The first operational point locates on minimum $d$-axis current excitation curve with around $40 \%$ and $22 \% \quad(=$ $4,=2.23$ ) selected which outputs $25 \%$ of rated torque. The result waveforms are shown in Fig 14(a), where phase currents wiggle and estimated position oscillates.

By contrast, Fig .14(b) shows the case with around $40 \%$ and $18 \% \quad(=1.76,=4.0)$, which operates on minimum $q$-axis current excitation curve. It also delivers $25 \%$ rated torque according to the constant torque curve shown in Fig 4. The harmonics of phase currents disappears and the estimated angle stays close to the actual encoder angle with almost zero angle estimation error shown in

\section{Back-EMF Method without Load (20Hz, 600rpm)}

Experiment $\mathrm{A}$ and $\mathrm{B}$ validate the proposed $q$-axis current injection towards the enhancement of sensorless operation using HFI at low speed. Experiment $\mathrm{C}$ and $\mathrm{D}$ try to demonstrate the back-EMF based sensorless control is still functioning after adopting proposed active $q$ flux concept as compared to conventional active $d$ flux method.

This section first tests the operation under no load condition. Fig .15(a) shows the waveforms of sensorless control with conventional active $d$ flux $(40 \%, 0 \quad$ ). The estimated angle 


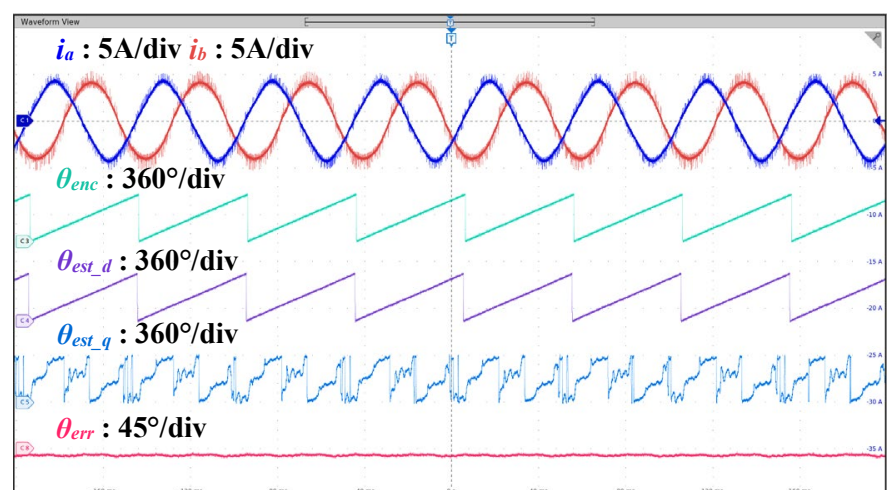

(a)

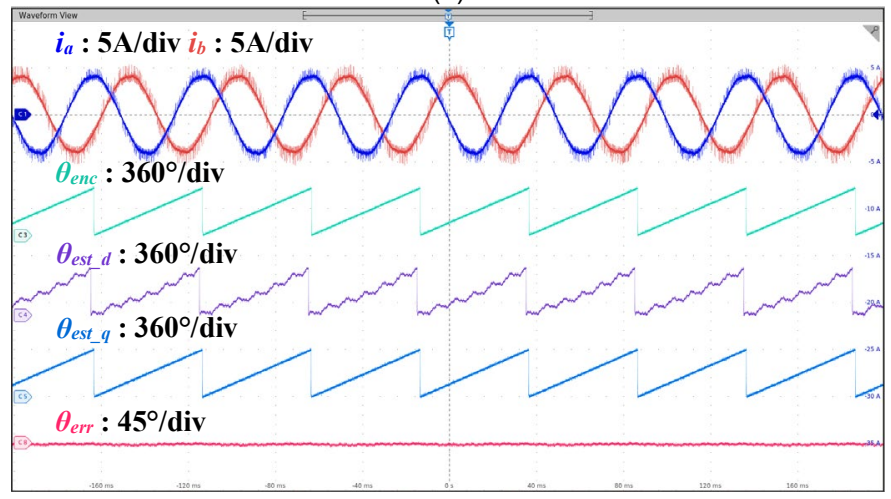

(b)

Fig. 15. Back-EMF based angle detection at no load condition. (a) active $d$ flux. (b) active q flux. Horizontal axis scale: $\mathbf{4 0 m s / d i v ~}$

using active $d$ flux method explained in Section III.B tracks encoder angle tightly. This is confirmed by , which is the difference between and . However, estimated angle using active $q$ flux described in Section IV.A.2) does not show a meaningful result. This is understandable because active $q$ flux does not exist when only $d$-axis current is injected.

Fig .15(b), on the other hand, presents the experiment result with proposed active $q$ flux $(0,40 \% \quad)$. This time, the estimated angle _ using active $q$ flux shows the promising result with smooth saw-tooth triangle. This is manifested in accordingly. Estimated angle using active $d$ flux shows considerable ripple because no $d$-axis current is commanded, albeit the angle of is still following the encoder feedback in average. This could attribute to the fact that part of $q$-axis flux runs through $d$-axis lamination when large $q$-axis current already saturates $q$-axis lamination.

\section{Back-EMF with Rated Load (20Hz, 600 rpm)}

Operating with rated torque on MTPA curve is essential to prove the effectiveness of the proposed sensorless control with active $q$ concept. Fig .16 shows sensorless control with rated torque output on MTPA curve ( = 4.78, = 8.72 ). Both active $d$ flux concept and active $q$ flux concept are exercised.

Under rated condition, both $d$-axis and $q$-axis currents are commanded to produce rated torque. Consequently, adequate $d$-axis and $q$-axis fluxes are excited for sensorless control using either active $d$ flux or active $q$ flux. Fig .16 shows a consistent angle detection depicted in before and after algorithm switch. In addition, the switch from sensorless control with

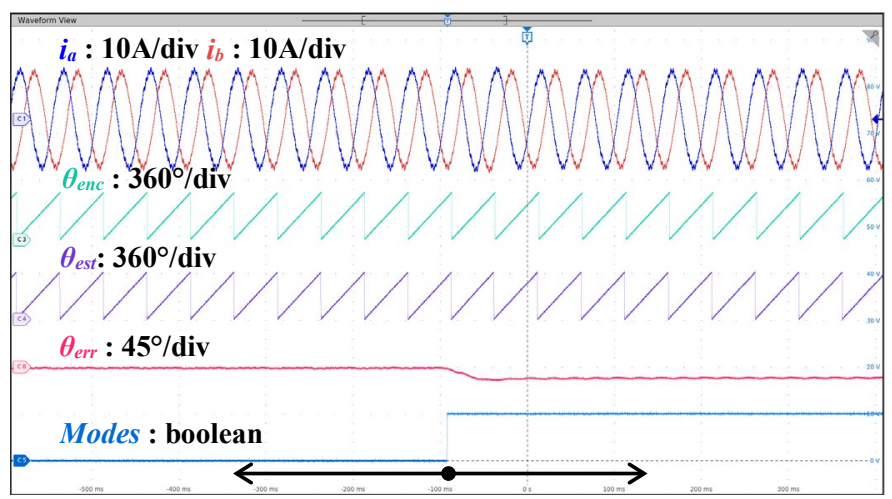

sensorless active $d$ flux sensorless active $q$ flux

Fig. 16. Back-EMF based angle detection with active $q$ flux concept at rated torque condition. Horizontal axis scale: $100 \mathrm{~ms} / \mathrm{div}$

active $d$ flux in left half of the figure to senseless control with active $q$ flux in right half is almost bumpless. However, the sensorless angle estimation accuracy varies with different methods as shown in . This will be further investigated.

\section{CONCLUSION}

In this paper, a position sensorless approach utilizing a minimum $q$-axis current was proposed for high- and low-speed operation of SynRM. In the low-speed range, using a minimum $q$-axis results in an operating trajectory which can improve the estimated rotor position and avoid regions of instability associated with HFI algorithms. Further, sensorless operation at high-speed using active $q$ flux concept was demonstrated. Using the same current trajectory across the entire speed range simplifies transitioning between high- and low-speed methods. The proposed concept was validated by experimental results.

\section{REFERENCES}

[1] A. Boglietti, A. Cavagnino, M. Pastorelli, D. Staton, and A. Vagati, "Experimental comparison of induction and synchronous reluctance motors performance," in Conf. Rec. IEEE IAS Annu. Meeting, 2005, pp. 474-479.

[2] N. Bianchi, "Synchronous reluctance and interior permanent magnet motors," in Proceedings - 2013 IEEE Workshop on Electrical Machines Design, Control and Diagnosis, WEMDCD 2013, Mar. 2013, pp. 75-94.

[3] A. Yousefi-Talouki, P. Pescetto, G. Pellegrino, and I. Boldea, "Combined active flux and high-frequency injection methods for sensorless direct-flux vector control of synchronous reluctance machines," IEEE Trans. Power Electron., vol. 33, no. 3, pp. 2447-2457, 2018.

[4] A. Yousefi-Talouki, P. Pescetto, and G. Pellegrino, "Sensorless direct flux vector control of synchronous reluctance motors including standstill, MTPA, and flux weakening," IEEE Trans. Ind. Appl., vol. 53, no. 4, pp. 3598-3608, 2017.

[5] F. J. W. Barnard;, W. T. Villet; and M. J. Kamper, "Hybrid active-flux and arbitrary injection position sensorless control of reluctance synchronous machines," IEEE Trans. Ind. Appl., vol. 51, no. 5, pp. 3899 3906, 2015.

[6] T. Tuovinen and M. Hinkkanen, "Adaptive full-order observer with high-frequency signal injection for synchronous reluctance motor drives," IEEE J. Emerg. Sel. Top. Power Electron., vol. 2, no. 2, pp. 181$189,2014$.

[7] S. C. Agarlita, I. Boldea, and F. Blaabjerg, "High-frequency-injection-assisted 'active-flux'-based sensorless vector control of reluctance synchronous motors, with experiments from zero speed," IEEE Trans. Ind. Appl., vol. 48, no. 6, pp. 1931-1939, 2012.

[8] E. Capecchi, P. Guglielmi, M. Pastorelli, and A. Vagai, "Position-sensorless control of the transverse-laminated synchronous reluctance motor," IEEE Trans. Ind. Appl., vol. 37, no. 6, pp. 1768-1776, 2001. 
[9] S. J. Kang, J. M. Kim, and S. K. Sul, "Position sensorless control of synchronous reluctance motor using high frequency current injection," IEEE Trans. Energy Convers., vol. 14, no. 4, pp. 1271-1275, 1999.

[10] I. Boldea, M. C. Paicu, and G. D. Andreescu, "Active flux concept for motion-sensorless unified AC drives," IEEE Trans. Power Electron., vol. 23, no. 5, pp. 2612-2618, 2008.

[11] M. Hinkkanen, P. Pescetto, E. Mölsä, S. E. Saarakkala, G. Pellegrino, and R. Bojoi, "Sensorless self-commissioning of synchronous reluctance motors at standstill without rotor locking," IEEE Trans. Ind. Appl., vol. 52, no. 4, pp. 3083-3092, 2016.

[12] N. Bedetti, S. Calligaro, and R. Petrella, "Stand-Still self-identification of flux characteristics for synchronous reluctance machines using novel saturation approximating function and multiple linear regression," IEEE Trans. Ind. Appl., vol. 52, no. 4, pp. 3083-3092, 2016.

[13] A. Vagati, M. Pastorelli, and G. Franceschini, "High-performance control of synchronous reluctance motors," IEEE Trans. Ind. Appl., vol. 33, no. 4, pp. 983-991, 1997.

[14] P. L. Jansen and R. D. Lorenz, "Transducerless position and velocity estimation in induction and salient AC machines," IEEE Trans. Ind. Appl., vol. 31, no. 2, pp. 240-247, 1995.

[15] M. Schroedl, "Sensorless control of AC machines at low speed and standstill based on the" INFORM" method," in Conf. Rec. IEEE-IAS Annu. Meeting, 1996, pp. 270-277.

[16] J. Cilia, G. M. Asher, K. J. Bradley, and M. Sumner, "Sensorless position detection for vector-controlled induction motor drives using an asymmetric outer-section cage," IEEE Trans. Ind. Appl., vol. 33, no. 5, pp. 1162-1169, Sep. 1997.

[17] J. H. Jang, S. K. Sul, J. I. Ha, K. Ide, and M. Sawamura, "Sensorless drive of surface-mounted permanent-magnet motor by high-frequency signal injection based on magnetic saliency," IEEE Trans. Ind. Appl., vol. 39, no. 4, pp. 1031-1039, Jul. 2003.

[18] J. I. Ha and S. K. Sul, "Sensorless field orientation control of an induction machine by high frequency signal injection," in Proc. IECON'94, 1997, vol. 1, pp. 426-432.

[19] Y. D. Yoon, S. K. Sul, S. Morimoto, and K. Ide, "High-bandwidth sensorless algorithm for AC machines based on square-wave-type voltage injection," IEEE Trans. Ind. Appl., vol. 47, no. 3, pp. 1361-1370, May 2011.

[20] P. Guglielmi, M. Pastorelli, and A. Vagati, "Impact of cross-saturation in sensorless control of transverse-laminated synchronous reluctance motors," IEEE Trans. Ind. Electron., vol. 53, no. 2, pp. 429-439, 2006.

[21] A. Vagati, "Synchronous reluctance solution: a new alternative in a.c. drives," in Proc. IECON'94, 1994, vol. 1, pp. 1-13.

[22] N. Bianchi, S. Bolognani, D. Bon, and M. D. Pré, "Rotor flux-barrier design for torque ripple reduction in synchronous reluctance and PM-assisted synchronous reluctance motors," IEEE Trans. Ind. Appl., vol. 45 , no. 3, pp. 921-928, 2009.

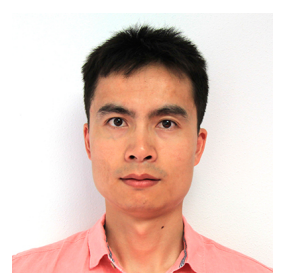

Zhendong Zhang (S'09-M'14) received his B.S. degree in 2006 in electrical engineering, from Southeast University, Nanjing, China. He was a graduate student at Tsinghua University from 2006 to 2008 . From 2008 to 2013 , He was pursuing his Ph.D. degree in the department of electrical engineering at The Ohio State University.

$\mathrm{He}$ was an intern with United Technology Research Center (UTRC) in 2013. He is now with Standard Drives Division, Rockwell Automation, Mequon, WI. His primary interest is the application of power electronics to variable-speed drive and its applications.

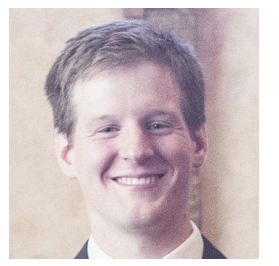

Jacob Lamb (S'14-M'17) received the B.S. degree in mathematics and the B.S.E. degree in electrical engineering from Northern Arizona University, Flagstaff, AZ, USA, both in 2013 , and the Ph.D. degree in electrical engineering from Kansas State University, Manhattan, KS, USA, in 2017.

$\mathrm{He}$ is currently a Senior Firmware/Control Engineer with Rockwell Automation, Mequon, WI, USA. His research interests include power electronics and switching algorithms for fault tolerance in reconfigurable converters. 